\title{
Social-communicative and attention problems in infancy and toddlerhood as precursors of preschool autistic traits
}

\author{
Esmé Möricke $^{1}$ (1) Corina U. Greven ${ }^{2,3,4} \cdot$ Janne C. Visser ${ }^{3} \cdot$ Iris J. Oosterling ${ }^{3} \cdot$ Jan K. Buitelaar ${ }^{2,3}$. \\ Nanda N. J. Rommelse (1,3) $^{10}$
}

Received: 3 June 2018 / Accepted: 30 December 2018

(C) The Author(s) 2019

\begin{abstract}
This longitudinal study focused on early behavioural problems and autistic traits. In a stratified, population-derived sample of 119 children, mothers reported through questionnaires on externalizing, internalizing, and social-communicative characteristics of their child in infancy (14 months) and toddlerhood (37 months), and on autistic traits at preschool age (4-5 years). Children with consistently normal behaviour from infancy to toddlerhood showed lower autistic traits at preschool age than children with deviant behaviour on one or both time points. High autistic traits at preschool age were predominantly preceded by problems in interaction, communication, language, play, and affect in infancy and/or toddlerhood, but also by inattention in toddlerhood. Adequate support and specific interventions in these domains are needed in an attempt to diminish further derailment of the child's behaviour and development, and to prevent the full manifestation of ASD or related disorders such as ADHD.
\end{abstract}

Keywords Social-communicative problems · Inattention · Autistic traits · Early childhood · Longitudinal transition · General population

\section{Introduction}

Autism spectrum disorders (ASD) are characterized by serious impairments in communication and social interaction as well as by stereotyped and repetitive interests, behaviours, and activities that mostly have their onset in the first years of life (American Psychiatric Association 2013). In severe forms and nearly always in combination with general

Esmé Möricke

Esme.Moricke@radboudumc.nl

1 Department of Psychiatry (966), Nijmegen Centre for Evidence-Based Practice, Radboud University Medical Centre, P.O. Box 9101, 6500 HB Nijmegen, The Netherlands

2 Department of Cognitive Neuroscience, Donders Institute for Brain, Cognition and Behaviour, Radboud University Medical Centre, Nijmegen, The Netherlands

3 Karakter Child and Adolescent Psychiatry University Centre, Nijmegen, The Netherlands

4 Medical Research Council Social, Genetic and Developmental Psychiatry Centre, Institute of Psychiatry, Psychology and Neuroscience, King's College London, London, UK developmental delay, autistic traits are already clearly detectable within the first two years after birth, for instance, when babbling, pointing, or gesturing is absent, the response to contextual cues, initiation of social interaction, or play is limited, appropriate eye contact or gaze is lacking, and/or repetitive movements with the body or objects are made (Jones et al. 2014; Nadel and Poss 2007; Saint-Georges et al. 2010; Volkmar et al. 2005; Yirmiya and Charman 2010). For milder forms of ASD, which tend to be diagnosed at a later age, detection of autistic traits in infancy or toddlerhood is more complicated. Children with milder forms are usually higher functioning, and may initially display only few and subtle symptoms (Ozonoff et al. 2015). Moreover, it is possible that these milder social-communicative problems are preceded or accompanied by more obvious externalizing behavioural problems outside the core domains of ASD, as overlap in risk factors and presentation with other neurodevelopmental disorders like attention-deficit hyperactivity disorder (ADHD) appears substantial (Johnson et al. 2015; Leitner 2014; Mayes et al. 2012; Van der Meer et al. 2012; Visser et al. 2013).

Most studies on the precursors and early identification of ASD have been conducted in clinical samples, referred 
samples, or genetically high-risk groups (i.e. baby siblings of older children diagnosed with ASD) (Brian et al. 2015; Oosterling et al. 2010; Sacrey et al. 2015), whereas milder or later-emerging expressions of ASD in general population samples have received less attention (Deconinck et al. 2013). Naturally, all designs come with their own merits, and may complement each other. However, in the former type of studies, parents and clinicians may be biased towards being relatively more aware of precursors and symptoms of ASD, which may lead to an overestimation, whereas in the latter type of studies, families are generally less biased by prior experiences with a proband with ASD. Other advantages of population-derived studies are that firstborns can be studied, and that less genetically driven forms of ASD may be characterized by particular phenotypic profiles. Prospective population-derived studies demonstrated that children with subtler or later-emerging forms of ASD already showed early impairments in social-communicative skills (Barbaro and Dissanayake 2013) and were delayed in social, language, cognitive, and motor development (Lemcke et al. 2013). Furthermore, problems regarding repetitive behaviour, imitation, play, temperament, hearing, vision, feeding, and bowel/ stool habits also seemed to unfold and differentiate during development (Bolton et al. 2012).

As such, this suggests that children from populationderived samples with subtler or later forms of ASD show (mild) core autistic traits and early emerging developmental problems in other areas, but less is known about preceding or co-occurring behavioural problems. It may be argued that particularly in less clear, later developing ASD also other indicators, like internalizing and externalizing (foremost ADHD) problems, may be present. However, this is not well documented and will be examined as the aim of this epidemiological study. In a longitudinal, stratified (low, middle, high risk) population-derived sample, we investigated through parental questionnaires which social-communicative problems and broader behavioural problems in infancy and toddlerhood preceded high autistic traits in the preschool period.

\section{Methods}

\section{Participants and procedure}

The design and study procedures were approved by the Medical Ethical Committee of University Utrecht Medical Centre. This study was part of a large screening research into the social development of young children (SOSO project). The original sample was a large general population birth cohort of all children born between August 2000 and August $2001(N=12,297)$ in the province of Utrecht, The Netherlands. At age 14 months (T1) parents of 6330 children
(51.5\%) and at age 37 months (T2) parents of 4237 children (34.5\%) filled in questionnaires about the child's behaviour. For more information, see Möricke et al. (2013, 2014). The latter group with measurements at both $\mathrm{T} 1$ and $\mathrm{T} 2$ formed the total population for the present study (T3, age 4-5 years). Due to constraints in time and money, we were forced to limit the number of participants at this stage of the study.

We contacted a subsample of 188 families, of which 119 (63.3\%) consented to participate after a complete explanation of the procedure. A random and weighted selection took place on the basis of child scores on the Early Screening of Autistic Traits Questionnaire (ESAT; Dietz et al. 2006; Swinkels et al. 2006), a questionnaire that was developed and tested as part of the SOSO project. The sensitivity for ASD and the specificity to distinguish normal from abnormal behaviour (including ASD and ADHD) were both high. The reliability and validity was also described in another previous study (Van Daalen et al. 2009). This questionnaire, administered when the child was 14 months old, consists of 14 items with "yes" (1) and "no" (0) answers. The items are based on early symptoms of ASD and cover the domains of social-communicative skills, reactions to sensory stimuli, stereotyped behaviour, and play. Generally, children with a score of three or more are considered to be screen-positive and thus at high risk for developing ASD. However, we used a cut-off of two or more, because we were also interested in children with milder autistic traits. The division over the ESAT scoring groups was as follows: low (score 0) 39.5\%, moderate (score 1) $36.1 \%$, and high (score $\geq 2$ ) $24.4 \%$ (see Fig. 1). It turned out that boys $(n=71 ; 59.7 \%)$ were overrepresented in comparison with girls $(n=48 ; 40.3 \%)$, but the proportion was almost similar in the three ESAT scoring groups $\left(\chi^{2}=0.62 ; d f=2 ; p=0.74\right)$.

The behaviour and development of these 119 children was evaluated three times by means of parental questionnaires (see also Instruments): Utrecht Screening Questionnaire (USQ) at T1 (age $M=14.48$ months; $\mathrm{SD}=0.51)$, Social Behaviour Questionnaire $(\mathrm{SBQ})$ at $\mathrm{T} 2$ (age $M=37.32$ months; $\mathrm{SD}=2.43$ ), and Social Communication Questionnaire (SCQ) at T3 (age $M=52.58$ months; $\mathrm{SD}=4.60)$. At T3, 12 children had high scores $(\geq 11)$ on the SCQ, including three children (2.5\%) with a formal ASD diagnosis as assessed by other professionals. Further, the questionnaires hardly revealed information about medical concerns or clinical diagnoses.

Unfortunately, not all approached families could take part. Reasons for non-participation included unreachability, unwillingness to cooperate, incompleteness of questionnaires, incorrectness of child data, multiple handicaps of the child, etc. Because access to information about nonresponders was not allowed on ethical grounds regarding privacy, we investigated possible selection bias by comparing the data of responders with demographic data 


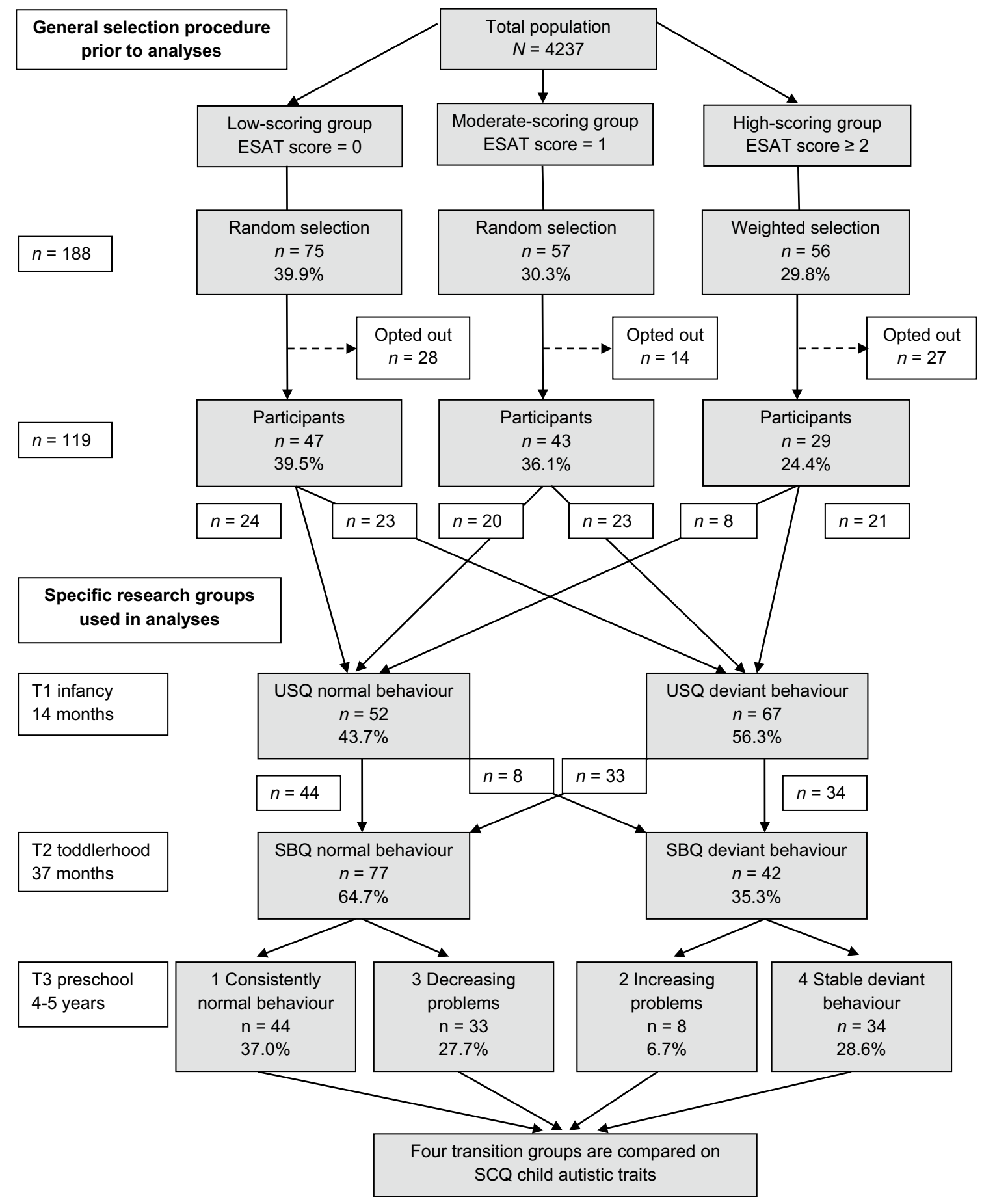

Fig. 1 Flow chart of participants

for the general population (Central Office for Statistics 2003). Of the children in the sample, $95.8 \%$ was Dutch $(n=114)$ and $4.2 \%$ non-Dutch $(n=5)$. Our sample contained more Dutch children than the population average $(82.1 \%)$. Especially fathers had a higher educational level (college or university degree) compared to individuals in the general population (fathers 50.4 vs. $36.0 \%$; mothers
42.0 vs. $38.9 \%$ ). The socio-economic status (SES), based on mean level of education and occupation of both parents, varied from low $(n=15 ; 12.6 \%)$ through moderate $(n=48$; $40.3 \%)$ to high $(n=56 ; 47.1 \%)$. Families with low SES were underrepresented, and families with high SES were overrepresented. Possibly, autochthonous and higher educated parents have more interest and means to participate 
in this kind of research than allochthonous and lower educated parents, which explains the skewed distribution.

\section{Instruments}

\section{T1: 14 months: Utrecht Screening Questionnaire}

The Utrecht Screening Questionnaire is fully described elsewhere (USQ; Beernink et al. 2007). It includes 74 items on externalizing, internalizing, or social-communicative problems suitable for children younger than 18 months. Previous exploratory factor analyses revealed nine factors underlying the USQ (Möricke et al. 2013), namely deviant communication, negative emotionality, deviant reactive behaviour, deviant play behaviour, demanding behaviour, social anxiety/inhibition, advanced social interaction problems, basic social interaction problems, and sleep problems. For examples of items, see Table 1. When considering all items together, internal consistency was good $(\alpha=0.82)$ and variance explained was $71.7 \%$. Latent class analyses showed that children could be divided into five classes, labelled (1) normal behaviour, (2) normal behaviour with mild negative behaviour, (3) communication and interaction problems, (4) moderate communication problems, and (5) negative and demanding behaviour.
Table 1 Item examples of factors at $\mathrm{T} 1$ (14 months) and T2 (37 months)

\begin{tabular}{|c|c|}
\hline USQ T1 14 months & SBQ T2 37 months \\
\hline 1 Deviant communication & 1 Language problems \\
\hline Uses gestures appropriately to express him/herself & Talks in full sentences \\
\hline Points at things to show & Participates in reciprocal social interaction \\
\hline \multicolumn{2}{|l|}{ Understands at least ten words } \\
\hline \multicolumn{2}{|l|}{ Uses common names like "mummy/daddy" } \\
\hline 2 Negative emotionality & 2 Negative emotionality \\
\hline Is stubborn, sullen or irritable & Is stubborn, sullen, or irritable \\
\hline Changes mood suddenly & Changes mood suddenly \\
\hline Screams a lot & Seems unhappy without clear reason \\
\hline Is easily upset & Is uncooperative \\
\hline 3 Deviant reactive behaviour & 3 Attention-deficit/hyperactivity problems \\
\hline Reacts when being spoken to & Cannot sit still; is restless or hyperactive \\
\hline Reacts normally to sensory stimuli & Cannot concentrate or pay attention for long \\
\hline 4 Deviant play behaviour & 4 Deviant play behaviour \\
\hline Plays with different toys/objects & Plays in various ways \\
\hline Plays in various ways & Plays with different toys/objects \\
\hline 5 Demanding behaviour & 5 Demanding behaviour \\
\hline Demands must be met immediately & Wants a lot of attention \\
\hline Has angry moods & $\begin{array}{l}\text { Cannot stand waiting; wants everything } \\
\text { now }\end{array}$ \\
\hline 6 Social anxiety/inhibition & 6 Deviant affective behaviour \\
\hline Shows interest in other children/adults & Shows clear facial expressions \\
\hline Is afraid of certain animals, things or places & Emotions are understandable \\
\hline 7 Advanced social interaction problems & 7 Communication and interaction problems \\
\hline Shows that he/she distinguishes parents from others & Directs social smile to parents and others \\
\hline Babbles or makes noises spontaneously & Follows glance of parents \\
\hline Follows with eyes when someone moves & $\begin{array}{l}\text { Uses sounds or words to get attention or } \\
\text { help }\end{array}$ \\
\hline & Reacts when being spoken to \\
\hline \multicolumn{2}{|l|}{8 Basic social interaction problems } \\
\hline \multicolumn{2}{|l|}{ Directs social smile to parents and others } \\
\hline \multicolumn{2}{|l|}{ Makes eye contact easily } \\
\hline 9 Sleep problems & 8 Sleep problems \\
\hline Cannot sleep alone & Cannot sleep alone \\
\hline Finds it difficult to fall asleep & Finds it difficult to fall asleep \\
\hline
\end{tabular}

A complete overview of items can be found in Möricke et al. (2014) 


\section{T2: 37 months: Social Behaviour Questionnaire}

The Social Behaviour Questionnaire (SBQ) consists of 62 items and focuses on externalizing, internalizing, and socialcommunicative behaviour of toddlers. By means of exploratory factor analyses, the items could be grouped in eight factors (Möricke et al. 2014): language problems, negative emotionality, attention-deficit/hyperactivity problems, deviant play behaviour, demanding behaviour, deviant affective behaviour, communication and interaction problems, and sleep problems. For examples of items, see Table 1. When considering all items together, internal consistency was good $(\alpha=0.84)$ and variance explained was $72.5 \%$. Again, latent class analyses disclosed that five classes of children could be distinguished, namely (1) normal behaviour, (2) normal behaviour with mild negative behaviour, (3) communication and interaction problems with negative behaviour, (4) normal behaviour with mild communication and interaction problems, and (5) negative and demanding behaviour.

\section{T3: 4-5 years: Social Communication Questionnaire}

Autistic traits at age $4-5$ years were measured with the Dutch version of the Social Communication Questionnaire (SCQ; Berument et al. 1999; Warreyn et al. 2004). Four domains are covered: reciprocal social interaction, language and communication, repetitive and stereotyped behaviour, and other behaviour. It consists of 40 items with "yes" and "no" answers. Twenty-five items were reversely coded so that typical behaviour was scored as 0 , and the lack of competences or the experience of problems was rated as 1 . On each questionnaire, maximally two missing values per domain and four in total were allowed ( $<10 \%$ of 40 items). These missing values were replaced by the individual domain means (domain score divided by the number of completed items). The minimum total score is 0 , and the maximum total score is 34 or 39 , depending on the absence or presence of language and speech, respectively. The official cut-off for ASD is fixed at 15, but for younger children a lower cut-off of 11 seems to be more accurate (Allen et al. 2007; Corsello et al. 2007; Wiggins et al. 2007). Since we focused on children aged 4-5 years, we chose the latter one to distinguish normal from clinical behaviour. For the total scale, the internal consistency was very $\operatorname{good}(\alpha=0.90)$ and the variance explained was $42.2 \%$ (Berument et al. 1999).

\section{Statistical analyses}

The goal was to explore which behaviours and/or changes therein from 14 to 37 months of age preceded high autistic traits at age 4-5 years, solely based on parental questionnaire data and not on clinical anamneses. The statistical software package IBM SPSS Statistics 20 (2011) was used, applying a variable-based and a person-based approach.
The variable-based approach covered the clustering of separate items into empirically derived behavioural and developmental factors by means of exploratory factor analysis. The person-based approach was twofold.

In the first step was examined which USQ factors at T1 and SBQ factors at T2 were related to high SCQ scores at T3. The solutions of prior exploratory factor analyses at T1 (9 factors) and T2 (8 factors) in, respectively, 6330 infants and 4237 toddlers were solid. The individual factor scores of the children who participated at both time points were weighted so that the values varied between 0 and 1 . The sample was split in children with a high score in the research sample (SCQ $\geq 11)(n=12)$, on the one hand, and children with a low score in the research sample $(\mathrm{SCQ}<11)$ $(n=107)$ or unavailable SCQ score in the population sample $(n=4118)$, on the other hand. The mean weighted factor scores were calculated for the high and low/unknown scoring groups separately and then compared. Exact differences were computed with nonparametric Mann-Whitney tests. Standardized effect sizes (Cohen's $d$ ) were calculated and considered as small (0.20), medium (0.50), and large (0.80) (Cohen 1992). Correction for multiple testing was not applied, because that would have increased the chance of a type II error instead of a type I error.

In the second step was determined which homogeneous (latent) classes and derived (transition) groups existed. To prevent disintegration of data, and to enable comprehensible and meaningful analyses in the small sample at T3 $(n=119)$, the five latent classes as found in a large general population sample (Möricke et al. 2013, 2014) were reduced to two groups per time point (T1 USQ: classes 1 and 2 normal; classes 3, 4, and 5 deviant; T2 SBQ: classes 1, 2, and 4 normal; classes 3 and 5 deviant). Subsequently, children were categorized according to their longitudinal transition from infancy to toddlerhood. Four types of transition groups were formed: consistently normal behaviour (no or mild problems at $\mathrm{T} 1$ and $\mathrm{T} 2$ ), increasing problems (no or mild problems at $\mathrm{T} 1$, severe problems at $\mathrm{T} 2$ ), decreasing problems (moderate or severe problems at $\mathrm{T} 1$, no or mild problems at $\mathrm{T} 2$ ), and stable deviant behaviour (moderate or severe problems at $\mathrm{T} 1$ and $\mathrm{T} 2$ ). Then, the four groups were compared on child autistic traits (SCQ) at preschool age (T3) using Chi-square tests on dichotomized scores and ANOVAs on normalized scores. See also Fig. 1.

\section{Results}

\section{Different factor scores for children with high and low/unknown SCQ scores}

Spearman's rank correlation coefficients between USQ factors at T1, SBQ factors at T2, and SCQ domains at T3 were 
all below 0.60 , indicating multicollinearity was acceptably low. When comparing mean weighted factor scores, the high scoring children at T3 (SCQ $\geq 11, n=12$ ) differed significantly from the children with low/unknown SCQ scores $(n=4225)$ on the factors deviant communication $(p<0.01$, $d=2.40)$, basic social interaction problems $(p<0.01$, $d=1.06)$, advanced social interaction problems $(p=0.01$, $d=0.94)$, and deviant play behaviour $(p<0.01, d=0.83)$ as measured at T1. Further, both groups diverged considerably on the factors language problems ( $p<0.01, d=2.26)$, communication and interaction problems $(p<0.01, d=1.65)$, deviant affective behaviour $(p<0.01, d=1.51)$, and deviant play behaviour $(p<0.01, d=1.07)$ as measured at T2. These factors showed similarities with one of the core domains of ASD. In addition, at T2, both groups could also be distinguished on the factor attention-deficit/hyperactivity problems ( $p=0.02, d=0.44$ ), which was mainly due to inattention ("Cannot concentrate or pay attention for long", $p<0.01, d=0.87$ ) and not to hyperactivity ("Cannot sit still; is restless or hyperactive", $p=0.58, d=-0.20$ ). No significant differences were found on the factors deviant reactive behaviour and social anxiety/inhibition at $\mathrm{T} 1$, nor on the factors demanding behaviour, negative emotionality, and sleep problems at T1 and T2 (see Table 1 for item examples). See also Fig. 2.

\section{Differences in SCQ scores between longitudinal transition groups}

The crosstab with four groups had an unequal distribution of children $\left(\chi^{2}=16.03, d f=1, p<0.01\right)$, with the highest percentage for children with consistently normal behaviour (37.0\%), followed by children with stable deviant behaviour (28.6\%) and children with decreasing problems (27.7\%), and the lowest percentage for children with increasing problems (6.7\%). There were no differences in the boy/girl ratio per group $\left(\chi^{2}=1.39, d f=3, p=0.71\right)$ and no meaningful age differences at T1 $(F=0.27, p=0.85), \mathrm{T} 2(F=2.76, p=0.05)$, and T3 $(F=2.03, p=0.14)$. See also Table 2 .

To investigate whether the longitudinal transition from $\mathrm{T} 1$ to $\mathrm{T} 2$ was related to autistic traits at $\mathrm{T} 3$, the four groups were compared. They differed significantly when using the dichotomized SCQ scores $(<11$ or $\geq 11)\left(\chi^{2}=11.70, p<0.01\right)$, and marginally when considering the normalized SCQ scores $(F=2.56, p=0.06)$. The group with stable deviant behaviour

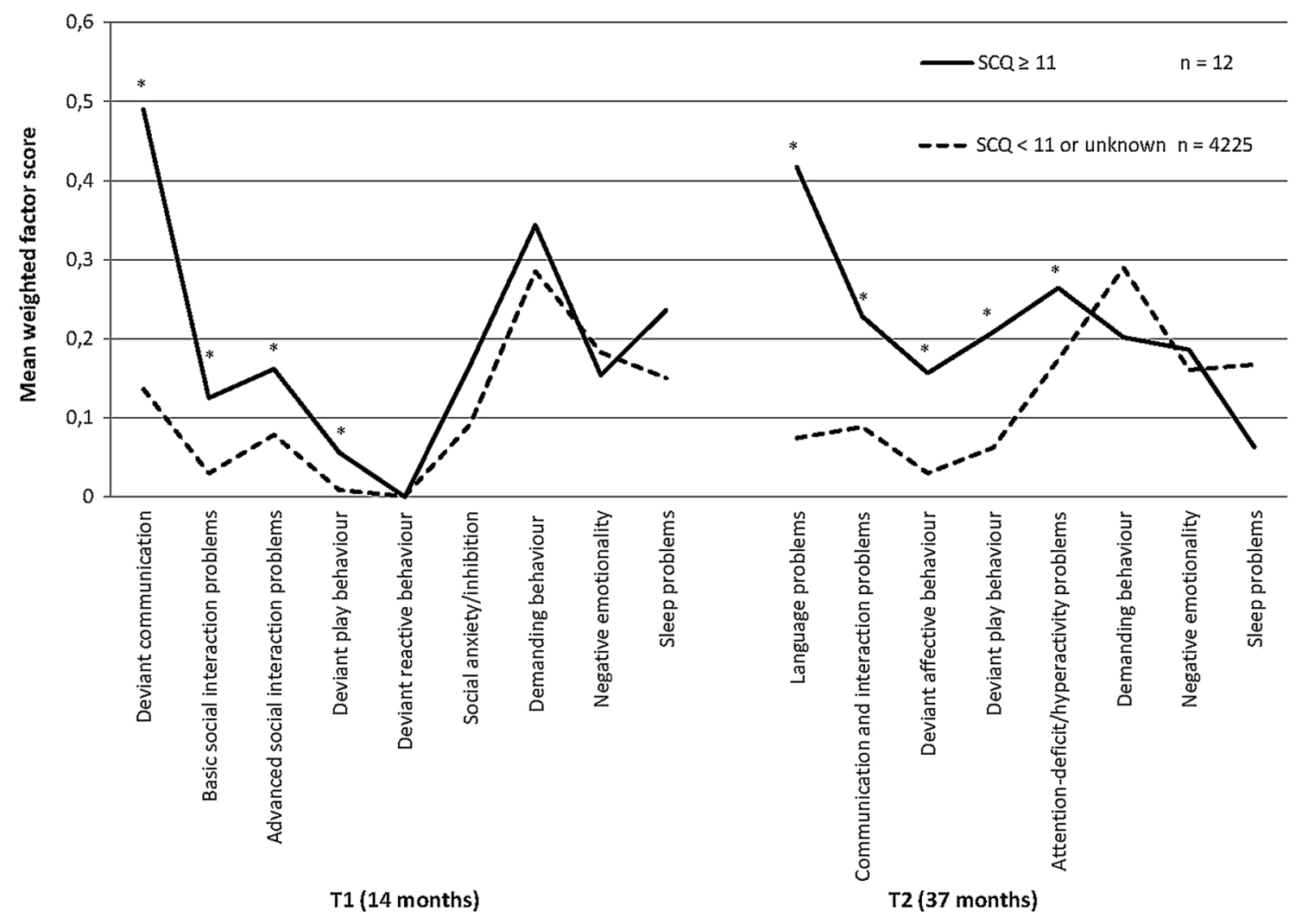

Fig. 2 Mean weighted factor scores of USQ (T1, 14 months) and SBQ (T2, 37 months) by SCQ scores ${ }^{\#}$ (T3, 4-5 years). *Significant difference in mean weighted factor score $(p<0.05)$. "SCQ scores were only known for 119 children included in the present research sample; 12 children had scores $\geq 11,107$ children had scores $<11$; for the remaining 4118 children, SCQ scores were unavailable 
scored highest $(M=0.32, \mathrm{SD}=0.94 ; 23.5 \% \mathrm{SCQ} \geq 11)$, and the group with consistently normal behaviour scored lowest $(M=-0.23, \mathrm{SD}=0.79 ; 0.0 \% \mathrm{SCQ} \geq 11)$; the groups with increasing and decreasing problems scored in between $(M=0.03, \mathrm{SD}=1.24 ; 12.5 \% \mathrm{SCQ} \geq 11$ and $M=-0.15$, $\mathrm{SD}=0.96 ; 9.1 \% \mathrm{SCQ} \geq 11$, respectively). See also Table 2 .

\section{Discussion}

In a longitudinal, stratified (low, medium, high risk) population-derived sample, we investigated through parental questionnaires which social-communicative problems and broader behavioural problems in infancy (age 14 months) and toddlerhood (age 37 months) preceded high autistic traits in the preschool period (age 4-5 years). Children with consistently normal behaviour from infancy to toddlerhood showed lower autistic traits at preschool age than children with deviant behaviour on one or both time points. Children with high autistic traits at age 4-5 years already had elevated scores on ASD-related factors at ages 14 and 37 months, but scored also high on inattention (as part of the factor ADHD problems) at age 37 months.

The finding that children with high autistic traits at age 4-5 years scored substantially (and mostly strongly) higher on deviant play, affective behaviour, social interaction and communication, as well as on language problems in infancy and/or toddlerhood converges with studies in high-risk samples (Jones et al. 2014). It also suggests that subtler and serious forms of ASD are quite alike in the type of precursors, although there may be variations in the number and severity of symptoms, depending on the sample. However, 9/12 (75.0\%) children in our general population sample had not received a formal diagnosis by the time of assessment (age 4-5 years). It is plausible that the questionnaires used are more suitable to identify general social-communicative problems than specific disorders within the autistic spectrum. This may implicate the need for improvement of adequate screening methods to detect (at least a subgroup of) children with abnormal developmental patterns potentially indicative of ASD, and to monitor their behaviour regularly and proactively, for instance, at well-baby clinics (Barbaro and Dissanayake 2009; Bradshaw et al. 2015; Oosterling et al. 2010; Zwaigenbaum et al. 2015a, b).

When zooming in on behaviours outside the ASD domain, high autistic traits at preschool age (4-5 years) were to a moderate degree preceded by increased levels of inattention in toddlerhood. This partly concurs with recent reviews showing overlap in developmental pathways towards ASD and ADHD at early age (Johnson et al. 2015; Leitner 2014; Visser et al. 2016), although the source or mechanism lying beneath inattention may be different in both disorders, and the expression of inattention at this young age may deviate from that in older children. However, in sharp contrast to findings in ADHD research (Arnett et al. 2013; SonugaBarke and Halperin 2010) and ASD studies (Clifford et al. 2013; Garon et al. 2016; Zwaigenbaum et al. 2013), high autistic traits were not preceded by increased levels of

Table 2 Descriptives of four groups at child age 14 months (T1), 37 months (T2), and 4-5 years (T3), and differences on child autistic traits at T3

\begin{tabular}{|c|c|c|c|c|c|c|c|}
\hline & & $\begin{array}{l}\text { Group } 1 \\
\text { T1 normal, T2 } \\
\text { normal }\end{array}$ & $\begin{array}{l}\text { Group } 2 \\
\text { T1 normal, T2 } \\
\text { deviant }\end{array}$ & $\begin{array}{l}\text { Group } 3 \\
\text { T1 deviant, T2 } \\
\text { normal }\end{array}$ & $\begin{array}{l}\text { Group } 4 \\
\text { T1 deviant, T2 } \\
\text { deviant }\end{array}$ & $\begin{array}{l}F ; p \\
\chi^{2} ; p\end{array}$ & Comparison; $p$ \\
\hline \multirow[t]{2}{*}{ Children $^{\mathrm{a}}$} & $N$ & 44 & 8 & 33 & 34 & \multirow[t]{2}{*}{$16.03 ;<0.01^{*}$} & \\
\hline & $\%$ of total & 37.0 & 6.7 & 27.7 & 28.6 & & \\
\hline \multirow[t]{2}{*}{ Sex (boys) } & $N$ & 29 & 4 & 18 & 20 & \multirow[t]{2}{*}{$1.39 ; 0.71$} & \\
\hline & $\%$ within group & 65.9 & 50.0 & 54.5 & 58.8 & & \\
\hline \multirow[t]{3}{*}{ Age in months } & $M(\mathrm{SD}) \mathrm{T} 1$ & $14.45(0.47)$ & $14.57(0.37)$ & $14.45(0.52)$ & $14.53(0.58)$ & $0.27 ; 0.85$ & \\
\hline & $M(\mathrm{SD}) \mathrm{T} 2$ & $38.11(2.34)$ & 36.85 (1.74) & $37.05(2.56)$ & $36.66(2.34)$ & $2.76 ; 0.05$ & \multirow[t]{2}{*}{$1>4 ; 0.05$} \\
\hline & $M(\mathrm{SD}) \mathrm{T} 3$ & $51.40(5.25)$ & $54.88(2.39)$ & $52.83(4.03)$ & $53.33(4.35)$ & $2.03 ; 0.14$ & \\
\hline \multirow{2}{*}{$\begin{array}{l}\text { SCQ } \geq 11 \text { Dichot- } \\
\text { omized score }\end{array}$} & $N$ & 0 & 1 & 3 & 8 & \multirow[t]{2}{*}{$11.70 ; 0.01^{*}$} & $1<2 ; 0.02^{*}$ \\
\hline & $\%$ within group & 0.0 & 12.5 & 9.1 & 23.5 & & $\begin{array}{l}1<3 ; 0.04^{*} \\
1<4 ;<0.01^{*}\end{array}$ \\
\hline $\begin{array}{l}\text { SCQ normalized } \\
\text { score }\end{array}$ & $M(\mathrm{SD})$ & $-0.23(0.79)$ & $0.03(1.24)$ & $-0.15(0.96)$ & $0.32(0.94)$ & $2.56 ; 0.06$ & \\
\hline
\end{tabular}

\footnotetext{
*Significant difference between groups $(p<0.05)$

${ }^{a}$ Division is based on 119 children. Comparison of four groups, $d f=3$

Groups were based on changes in broadly defined behavioural problems (externalizing, internalizing, and/or social-communicative)

$S C Q$ Social Communication Questionnaire
} 
demanding behaviour, negative emotionality, and sleep problems in infancy and toddlerhood in our population-derived sample. The difference may perhaps be explained by the severity of children's problem behaviours, with children in high-risk studies possibly having higher levels of co-occurring early regulation and externalizing problems compared to children in population studies. Furthermore, the items in our study may have been too low in number and specificity to measure these constructs adequately. Finally, the age differences between our sample and the samples in the studies mentioned previously may have played a role. If replicated, our findings may suggest that demanding behaviour, negative emotionality, and sleep problems are not very strong predictors of later-emerging ASD. Instead, these behaviours may be reflective of general difficult temperamental characteristics or regulation problems, which will only cascade towards disorders like ADHD in a proportion of children (Beernink et al. 2007; Gurevitz et al. 2014). However, these behaviours may also be quite normative at these young ages, and may disappear when the child grows older and learns to regulate emotions and behaviour.

The strengths of this study lie in the stratified populationderived sample, the early originating longitudinal assessments, and the broad focus on social-communicative problems as well as internalizing and externalizing behaviours. However, a main limitation is the low inclusion rate of $63 \%$ due to factors regarding contact and cooperation with parents, completeness and correctness of data, and child characteristics. Attrition is not uncommon in longitudinal studies (Teague et al. 2018). Besides, we ascertained that the included and excluded sample only differed in educational level and socio-economic status of the parents, but not in child age, gender, nationality, and initial ESAT score. The sample size was modest, especially of the group with increasing problems from infancy to toddlerhood $(n=8)$ and of the group of children with high autistic traits at age 4-5 years $(n=12)$. Because only three children had a formal ASD diagnosis at the time of investigation, it was difficult to make solid predictions. The comparison with the large population-derived sample revealed clinically relevant results with regard to high autistic traits in general, but was not suitable to draw conclusions about different pathways leading to various forms of ASD. Bigger samples with a larger number of children with high autistic traits as well as a more representative distribution of children among subgroups with regard to child sex, parental SES, and familial ethnicity will increase the validity of the results. Another limitation is that predictions of autistic traits were based on composed behavioural factors, but separate items may give more specific and concrete information, as was the case with the factor ADHD problems and the accompanying items. So, analyses on the item level may lead to stronger clues about early behaviour problems related to ASD or ADHD, and may offer new possibilities to improve screening and intervention tools. A final limitation is that we hardly used standardized measures with professionals as informants and mainly relied on parental reports. Data regarding child behaviour at age 14 and 37 months were given by only one parent, generally the mother. In future research, it is preferable to include more elaborate assessments and to gather information from both parents as well as other informants (day-care employees, preschool teachers, health care workers) at all time points so that more exact comparisons can be made.

In conclusion, the parental questionnaire data revealed that children with consistently normal behaviour from infancy to toddlerhood showed lower autistic traits at preschool age (4-5 years) than children with deviant behaviour on one or both time points. High autistic traits at preschool age are mainly and strongly preceded by early manifested and stable social-communicative problems in infancy and toddlerhood, and only to a moderate degree by other behavioural problems (inattention in toddlerhood). Regular monitoring by child care practitioners from a young age onwards is essential, especially when a continuation or increase of autistic traits is recognized. Adequate support and specific interventions in these domains are needed in an attempt to diminish further derailment of the child's behaviour and development, and to prevent the full manifestation of ASD or related disorders such as ADHD (Boyd et al. 2010; Dawson 2008; Dawson and Bernier 2013; Zwaigenbaum et al. 2013, 2015a).

Acknowledgements This research is part of the SOSO project which has been financially supported by the Dutch Organization for Scientific Research (ZonMw CZ-TT 940-38-045 Research Program Chronic Diseases) and by University Medical Centre Utrecht, Radboud University Medical Centre Nijmegen, and Karakter University Centre Nijmegen, The Netherlands. The research leading to these results has also received financial contributions from the Innovative Medicines Initiative Joint Undertaking (EU-AIMS 115300), the European Union's Seventh Framework Program (FP7/2007-2013), the European Federation of Pharmaceutical Industries and Associations (EFPIA) companies, and Horizon 2020 Marie Sklodowska-Curie ETN grant "Integrated view on disruptions of early brain development" (BRAINVIEW 642996). We are very grateful to all the parents who gave their informed consent and filled out the questionnaires.

\section{Compliance with ethical standards}

Conflict of interest In the past 3 years, Buitelaar has been a consultant to/member of advisory board of/and/or speaker for Janssen Cilag BV, Eli Lilly, Bristol-Myer Squibb, Schering Plough, UCB, Shire, Novartis and Servier. He is not an employee or a stock shareholder of any of these companies. He has no other financial or material support, including expert testimony, patents, and royalties. The other authors declare that they have no conflict of interest.

Ethical approval All procedures performed in this study involving human participants were approved by the institutional research committee. The study has been performed in accordance with the international 
ethical standards as laid down in the 1964 Declaration of Helsinki and its later amendments.

Informed consent Informed consent was obtained from all individual participants included in the study.

OpenAccess This article is distributed under the terms of the Creative Commons Attribution 4.0 International License (http://creativeco mmons.org/licenses/by/4.0/), which permits unrestricted use, distribution, and reproduction in any medium, provided you give appropriate credit to the original author(s) and the source, provide a link to the Creative Commons license, and indicate if changes were made.

\section{References}

Allen CW, Silove N, Williams K, Hutchins P (2007) Validity of the Social Communication Questionnaire in assessing risk of autism in preschool children with developmental problems. J Autism Dev Disord 37(7):1272-1278. https://doi.org/10.1007/s1080 3-006-0279-7

American Psychiatric Association (2013) Diagnostic and statistical manual of mental disorders, 5th edn. APA, Washington, DC

Arnett AB, MacDonald B, Pennington BF (2013) Cognitive and behavioural indicators of ADHD symptoms prior to school age. J Child Psychol Psychiatry 54(12):1284-1294. https://doi.org/10.1111/ jcpp.12104

Barbaro J, Dissanayake C (2009) Autism spectrum disorders in infancy and toddlerhood: a review of the evidence on early signs, early identification tools, and early diagnosis. J Dev Behav Pediatr 30(5):447-459. https://doi.org/10.1097/DBP.0b013e3181ba0f9f

Barbaro J, Dissanayake C (2013) Early markers of autism spectrum disorders in infants and toddlers prospectively identified in the Social Attention and Communication Study. Autism 17(1):64-86. https://doi.org/10.1177/1362361312442597

Beernink ACE, Swinkels SHN, Buitelaar JK (2007) Problem behavior in a community sample of 14- and 19-month-old children: common versus uncommon behaviors, structure, and stability. Eur Child Adolesc Psychiatry 16(4):271-280. https://doi.org/10.1007/ s00787-007-0600-9

Berument SK, Rutter M, Lord C, Pickles A, Bailey A (1999) Autism Screening Questionnaire: diagnostic validity. Br J Psychiatry 175:444-451. https://doi.org/10.1192/bjp.175.5.444

Bolton PF, Golding J, Emond A, Steer CD (2012) Autism spectrum disorder and autistic traits in the Avon Longitudinal Study of Parents and Children: precursors and early signs. J Am Acad Child Adolesc Psychiatry 51(3):249-260. https://doi.org/10.1016/j. jaac.2011.12.009

Boyd BA, Odom SL, Humphreys BP, Sam AM (2010) Infants and toddlers with autism spectrum disorder: early identification and early intervention. J Early Interv 32(2):75-98. https://doi. org/10.1177/1053815110362690

Bradshaw J, Steiner AM, Gengoux G, Koegel LK (2015) Feasibility and effectiveness of very early intervention for infants at risk for autism spectrum disorder: a systematic review. J Autism Dev Disord 45(3):778-794. https://doi.org/10.1007/s 10803-014-2235-2

Brian JA, Bryson SE, Zwaigenbaum L (2015) Autism spectrum disorder in infancy: developmental considerations in treatment targets. Curr Opin Neurol 28(2):117-123. https://doi.org/10.1097/ WCO.0000000000000182

Central Office for Statistics (Centraal Bureau voor Statistiek) (2003) CBS, Voorburg, The Netherlands

Clifford SM, Hudry K, Elsabbagh M, Charman T, Johnson MH, Team BASIS (2013) Temperament in the first 2 years of life in infants at high-risk for autism spectrum disorders. J Autism Dev Disord 43(3):673-686. https://doi.org/10.1007/s10803-012-1612-y

Cohen J (1992) A power primer. Psychol Bull 112(1):155-159. https ://doi.org/10.1037/0033-2909.112.1.155

Corsello C, Hus V, Pickles A, Risi S, Cook EH Jr, Leventhal BL, Lord C (2007) Between a ROC and a hard place: decision making and making decisions about using the SCQ. J Child Psychol Psychiatry 48(9):932-940. https://doi.org/10.1111/j.1469-7610.2007.01762.x

Dawson G (2008) Early behavioral intervention, brain plasticity, and the prevention of autism spectrum disorder. Dev Psychopathol 20(3):775-803. https://doi.org/10.1017/S0954579408000370

Dawson G, Bernier R (2013) A quarter century of progress on the early detection and treatment of autism spectrum disorder. Dev Psychopathol 25(4):1455-1472. https://doi.org/10.1017/S0954 579413000710

Deconinck N, Soncarrieu M, Dan B (2013) Toward better recognition of early predictors for autism spectrum disorders. Pediatr Neurol 49(4):225-231. https://doi.org/10.1016/j.pediatrneu rol.2013.05.012

Dietz C, Swinkels SHN, Van Daalen E, Van Engeland H, Buitelaar JK (2006) Screening for autistic spectrum disorder in children aged 14-15 months. II: population screening with the Early Screening of Autistic Traits Questionnaire (ESAT). Design and general findings. J Autism Dev Disord 36(6):713-722. https://doi. org/10.1007/s10803-006-0114-1

Garon N, Zwaigenbaum L, Bryson S, Smith IM, Brian J, Roncadin C, Vaillancourt T, Armstrong V, Sacrey LAR, Roberts W (2016) Temperament and its association with autism symptoms in a highrisk population. J Abnorm Child Psychol 44(4):757-769. https:// doi.org/10.1007/s10802-015-0064-1

Gurevitz M, Geva R, Varon M, Leitner Y (2014) Early markers in infants and toddlers for development of ADHD. J Atten Disord 18(1):14-22. https://doi.org/10.1177/1087054712447858

IBM Corporation (2011) IBM SPSS statistics for windows, Version 20.0. IBM Corp, Armonk, NY

Johnson MH, Gliga T, Jones E, Charman T (2015) Annual research review: infant development, autism, and ADHD — early pathways to emerging disorders. J Child Psychol Psychiatry 56(3):228-247. https://doi.org/10.1111/jcpp.12328

Jones EJH, Gliga T, Bedford R, Charman T, Johnson MH (2014) Developmental pathways to autism: a review of prospective studies of infants at risk. Neurosci Biobehav Rev 39:1-33. https://doi. org/10.1016/j.neubiorev.2013.12.001

Leitner Y (2014) The co-occurrence of autism and attention deficit hyperactivity disorder in children — what do we know? Front Hum Neurosci 8:268. https://doi.org/10.3389/fnhum.2014.00268

Lemcke S, Juul S, Parner ET, Lauritsen MB, Thorsen P (2013) Early signs of autism in toddlers: a follow-up study in the Danish National Birth Cohort. J Autism Dev Disord 43(10):2366-2375. https://doi.org/10.1007/s10803-013-1785-z

Mayes SD, Calhoun SL, Mayes RD, Molitoris S (2012) Autism and ADHD: overlapping and discriminating symptoms. Res Autism Spectr Disord 6(1):277-285. https://doi.org/10.1016/j. rasd.2011.05.009

Möricke E, Lappenschaar GAM, Swinkels SHN, Rommelse NNJ, Buitelaar JK (2013) Latent class analysis reveals five homogeneous behavioural and developmental profiles in a large Dutch population sample of infants aged 14-15 months. Eur Child Adolesc Psychiatry 22(2):103-115. https://doi.org/10.1007/s0078 7-012-0332-3

Möricke E, Lappenschaar GAM, Swinkels SHN, Rommelse NNJ, Buitelaar JK (2014) Different stability of social-communication problems and negative demanding behaviour from infancy to toddlerhood in a large Dutch population sample. Child Adolesc Psychiatry Ment Health 8:19. https://doi.org/10.1186/1753-2000-8-19 
Nadel S, Poss JE (2007) Early detection of autism spectrum disorders: screening between 12 and 14 months of age. J Am Acad Nurse Pract 19(8):408-417. https://doi.org/10.111 1/j.1745-7599.2007.00244.x

Oosterling IJ, Wensing M, Swinkels SH, Van der Gaag RJ, Visser JC, Woudenberg T, Minderaa R, Steenhuis MP, Buitelaar JK (2010) Advancing early detection of autism spectrum disorders by applying an integrated two-stage screening approach. J Child Psychol Psychiatry 51(3):250-258. https://doi.org/10.111 1/j.1469-7610.2009.02150.x

Ozonoff S, Young GS, Landa RJ, Brian J, Bryson S, Charman T, Chawarska K, Macari SL, Messinger D, Stone WL, Zwaigenbaum L, Iosif AM (2015) Diagnostic stability in young children at risk for autism spectrum disorder: a baby siblings research consortium study. J Child Psychol Psychiatry 56(9):988-998. https://doi. org/10.1111/jcpp.12421

Sacrey LAR, Bennett JA, Zwaigenbaum L (2015) Early infant development and intervention for autism spectrum disorder. J Child Neurol 30(14):1921-1929. https://doi.org/10.1177/0883073815 601500

Saint-Georges C, Cassel RS, Cohen D, Chetouani M, Laznik MC, Maestro S, Muratori F (2010) What studies of family home movies can teach us about autistic infants: a literature review. Res Autism Spectr Disord 4(3):355-366. https://doi.org/10.1016/j. rasd.2009.10.017

Sonuga-Barke EJS, Halperin JM (2010) Developmental phenotypes and causal pathways in attention deficit/hyperactivity disorder: potential targets for early intervention? J Child Psychol Psychiatry 51(4):368-389. https://doi.org/10.1111/j.1469-7610.2009.02195.x

Swinkels SHN, Dietz C, Van Daalen E, Kerkhof IHGM, Van Engeland H, Buitelaar JK (2006) Screening for autistic spectrum in children aged 14-15 months. I: the development of the Early Screening of Autistic Traits Questionnaire (ESAT). J Autism Dev Disord 6:723-732. https://doi.org/10.1007/s10803-006-0115-0

Teague S, Youssef GJ, Macdonald JA, Sciberras E, Shatte A, FullerTyszkiewicz M, Greenwood C, McIntosh J, Olsson CA, Hutchinson D, Lifecourse Sciences Theme SEED (2018) Retention strategies in longitudinal cohort studies: a systematic review and meta-analysis. BMC Med Res Methodol 18(1):151. https://doi. org/10.1186/s12874-018-0586-7

Van Daalen E, Kemner C, Dietz C, Swinkels SH, Buitelaar JK, Van Engeland H (2009) Inter-rater reliability and stability of diagnoses of autism spectrum disorder in children identified through screening at a very young age. Eur Child Adolesc Psychiatry 18(11):663-674. https://doi.org/10.1007/s00787-009-0025-8

Van der Meer JMJ, Oerlemans AM, Van Steijn DJ, Lappenschaar MGA, De Sonneville LMJ, Buitelaar JK, Rommelse NN (2012) Are autism spectrum disorder and attention-deficit/hyperactivity disorder different manifestations of one overarching disorder? Cognitive and symptom evidence from a clinical and populationbased sample. J Am Acad Child Adolesc Psychiatry 51(11):1160 1172. https://doi.org/10.1016/j.jaac.2012.08.024

Visser JC, Rommelse N, Vink L, Schrieken M, Oosterling IJ, Van der Gaag RJ, Buitelaar JK (2013) Narrowly versus broadly defined autism spectrum disorders: differences in pre- and perinatal risk factors. J Autism Dev Disord 43(7):1505-1516. https://doi. org/10.1007/s10803-012-1678-6

Visser JC, Rommelse NN, Greven CU, Buitelaar JK (2016) Autism spectrum disorder and attention-deficit/hyperactivity disorder in early childhood: a review of unique and shared characteristics and developmental antecedents. Neurosci Biobehav Rev 65:229-263. https://doi.org/10.1016/j.neubiorev.2016.03.019

Volkmar F, Chawarska K, Klin A (2005) Autism in infancy and early childhood. Annu Rev Psychol 56:315-336. https://doi. org/10.1146/annurev.psych.56.091103.070159

Warreyn P, Raymaekers R, Roeyers H (2004) Handleiding voor de Vragenlijst Sociale Communicatie (SCQ-NL). Stichting Integratie Gehandicapten (SIG), Destelbergen, Belgium

Wiggins LD, Bakeman R, Adamson LB, Robins DL (2007) The utility of the Social Communication Questionnaire in screening for autism in children referred for early intervention. Focus Autism Other Dev Disabil 22(1):33-38. https://doi.org/10.1177/10883 576070220010401

Yirmiya N, Charman T (2010) The prodrome of autism: early behavioral and biological signs, regression, peri- and post-natal development and genetics. J Child Psychol Psychiatry 51(4):432-458. https://doi.org/10.1111/j.1469-7610.2010.02214.x

Zwaigenbaum L, Bryson S, Garon N (2013) Early identification of autism spectrum disorders. Behav Brain Res 251:133-146. https ://doi.org/10.1016/j.bbr.2013.04.004

Zwaigenbaum L, Bauman ML, Choueiri R, Kasari C, Carter A, Granpeesheh D, Mailloux Z, Smith Roley S, Wagner S, Fein D, Pierce K, Buie T, Davis PA, Newschaffer C, Robins D, Wetherby A, Stone WL, Yirmiya N, Estes A, Hansen RL, McPartland JC, Natowicz MR (2015a) Early intervention for children with autism spectrum disorder under 3 years of age: recommendations for practice and research. Pediatrics 136:S60-S81. https://doi. org/10.1542/peds.2014-3667E

Zwaigenbaum L, Bauman ML, Fein D, Pierce K, Buie T, Davis PA, Newschaffer C, Robins DL, Wetherby A, Choueiri R, Kasari C, Stone WL, Yirmiya N, Estes A, Hansen RL, McPartland JC, Natowicz MR, Carter A, Granpeesheh D, Mailloux Z, Smith Roley S, Wagner S (2015b) Early screening of autism spectrum disorder: recommendations for practice and research. Pediatrics 136:S41S59. https://doi.org/10.1542/peds.2014-3667D 